\title{
ENTRE EL FASCISMO Y LA GUERRA: ELEMENTOS PARA UNA HISTORIA POLÍTICA DE LA COLONIA ITALIANA DE IQUIQUE, 1927-1943
}

\author{
BETWEEN FASCISM AND WAR: ELEMENTS FOR A POLITICAL \\ HISTORY OF THE ITALIAN COLONY IN IQUIQUE, 1927-1943
}

\author{
Alfonso Díaz Aguad* y Damián Lo Chávez**
}

\begin{abstract}
Este trabajo estudia la influencia del fascismo italiano en la colonia italiana de Iquique y el impacto de la política exterior italiana en la vida de los residentes italianos en Iquique. A su vez nos referiremos a las repercusiones de dichas influencias en la vida política y social de la ciudad de Iquique. Nuestra propuesta es que el fascismo correspondió a un vínculo reforzado con la madre patria, un sentimiento nacionalista renovado y un factor de cohesión cultural que duró mientras tuvo un entorno favorable en donde desarrollarse. Sin embargo, no fue una militancia comprometida con un impacto de largo alcance.
\end{abstract}

Palabras claves: Fascismo, Iquique, colonia italiana, nacionalismo, identidad, guerra.

This paper studies the influence of Italian fascism in the Italian colony of Iquique and the impact of Italian foreign policy on the lives of Italian residents in Iquique. In turn we will refer to the repercussions of these influences on the political and social life of the city of Iquique. Our proposal is that fascism corresponded to a reinforced bond with the mother country, a renewed nationalist feeling and a factor of cultural cohesion that lasted while it had a favorable environment in which to develop. However, it was not a militancy committed to a far-reaching impact.

Key words: Fascism, Iquique, italian colony, nationalism, identity, war.

\section{Introducción}

La década de 1920 vio aparecer una nueva identidad política en la ciudad de Iquique nacida de la confluencia de dos factores: ideología y nacionalidad. Esta identidad política se denominó fascismo italiano y se caracterizó por el origen nacional de sus componentes, italianos, y su adhesión a la figura de Benito Mussolini y el apoyo al régimen fascista de Italia (Imagen 1). Fue un fenómeno de múltiples dimensiones.

La presencia de núcleos de italianos fascistas fuera de Italia se relaciona con ciertos fenómenos de mayor alcance: la influencia del régimen italiano en el exterior, el gran auge en el periodo de los postulados ultranacionalistas, corporativistas, autoritarios, anticomunistas, etc. denominados en su conjunto de forma amplia e imprecisa como "fascismo", y la capacidad de una colonia extranjera de desarrollar una particular forma de identidad nacional identificada con un tipo particular de política e ideología. Es importante mencionar que el caso de las influencias fascistas en Iquique no fue el único de su tipo en Chile y en América Latina: sucedió en cada ciudad con notoria presencia de inmigrantes italianos: Valparaíso, La Paz, Tacna, Lima, Buenos Aires, Ciudad de México, São Paulo, por nombrar algunos ejemplos. Este trabajo no es una historia del fascismo a nivel nacional ni continental, tampoco es una historia de la migración italiana a Tarapacá y ni del establecimiento de una colonia permanente de italianos residentes en la ciudad de Iquique. Es una aproximación a un fenómeno donde se intersectan ambos elementos: política e identidad nacional, migración e ideología. Este trabajo se enmarca en lo que se ha denominado Nueva Historia Política, es decir, la propuesta de un retorno a lo político desde nuevas miradas que divergen de la historia política tradicional, centrándonos en nuevas dimensiones ajenas a la política estrictamente institucional, mirada y desarrollada por la historiadora recientemente fallecida Olga Ulianova (Ulianova, 2009). Entre estas dimensiones figuran las redes, las experiencias cotidianas, las militancias, las subjetividades, las ideas y la cultura de un fenómeno político en particular. Utilizamos prensa, archivos históricos y

\footnotetext{
* Universidad de Tarapacá, Departamento de Ciencias Históricas y Geográficas. Arica, Chile. Correo electrónico: adiaz@uta.cl

** Universidad de Tarapacá, Programa de Magíster en Historia. Departamento de Ciencias Históricas y Geográficas. Arica, Chile. Correo electrónico: damianernesto.lo@gmail.com
} 


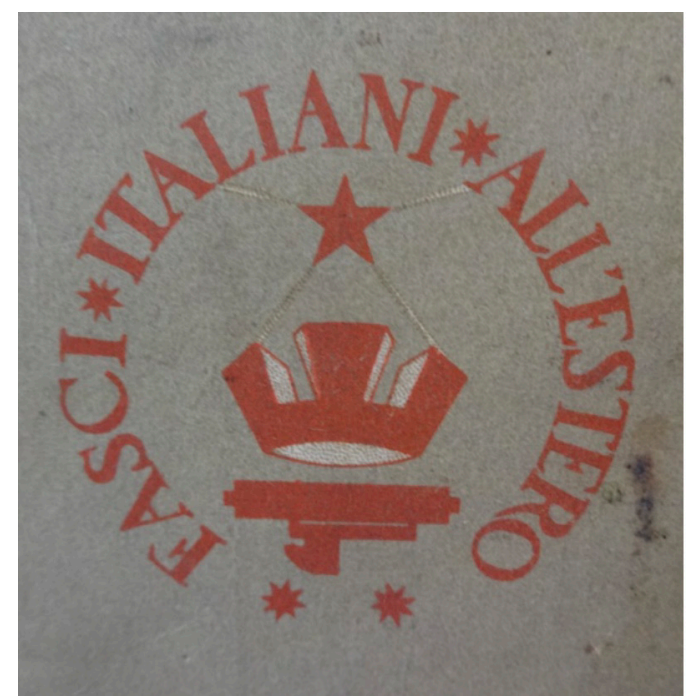

Imagen 1. Emblema del fascio italiano en el exterior, impreso en una publicación fascista de adoctrinamiento juvenil titulada Quando il mondo era Roma. Propiedad de Mikele Manielo.

testimonios orales que nos permitieron reconstruir las distintas dimensiones que tuvo tanto a nivel personal como colectivo la adhesión de la colonia italiana de Iquique al fascismo.

\section{Migración italiana en Tarapacá}

A partir de la década de 1870 comenzó a implementarse el sistema Shanks en las oficinas salitreras de Tarapacá, dando inicio al periodo denominado Ciclo de Expansión del Salitre que se extendería hasta la crisis de 1930. Este periodo se caracterizó por la producción industrial a gran escala y una amplia red de servicios en torno a ella: trenes, almacenes, comercio, fundiciones, muelles, etc. A raíz de ello, la provincia de Tarapacá y el puerto de Iquique se volvieron atractivos escenarios en donde emprender negocios e invertir capitales para inmigrantes de origen europeo. Entre estos últimos se encontraría un gran contingente de italianos, dedicados en su minoría a la producción salitrera y en su mayoría al comercio en toda clase de rubros. Está pendiente hacer un estudio detallado y extensivo de la migración italiana en Tarapacá, ya que es una colonia que se arraigó notoriamente en la zona y perduró más allá de la crisis de 1930. Entre sus miembros se cuentan destacados personajes de la historia local y sus apellidos resuenan en diversos ámbitos hasta la fecha. Sin embargo existen algunos estudios introductorios que nos permiten hacernos un panorama relativamente completo del asentamiento de italianos en Tarapacá en las décadas que preceden a la Marcha sobre Roma y al surgimiento de una identidad política de carácter fascista en la colonia. Marcos Calle hace un buen resumen de elementos cuantitativos en torno a la inmigración italiana a la provincia sobre la base de censos, registros de matrimonios, profesiones y sociedades comerciales. Concluye que a lo largo de un periodo comprendido entre 1865 y 1920, los italianos fueron la segunda mayoría de inmigrantes europeos, siempre detrás de la colonia británica que lideraba las estadísticas. A diferencia de los británicos, los italianos tuvieron una participación minoritaria como capitalistas en la industria salitrera, pero sí una fuerte presencia en el comercio minorista, las pulperías, la hotelería y las fábricas de alimentos en la ciudad de Iquique (2013). Sin embargo, el estudio de Calle se centra casi exclusivamente en lo cuantitativo, dejando fuera elementos identitarios y culturales. Alfonso Díaz, por otra parte, sintetiza algunos elementos adicionales de la presencia italiana en Tarapacá. Es difícil establecer con certeza la presencia de italianos durante la Colonia, pero sin duda sabemos que ya eran una colonia asentada al momento de estallar la Guerra del Pacífico y que mantuvieron una relativa neutralidad en los hechos con una participación limitada a la colaboración con el orden público y la defensa de la propiedad privada. Lo mismo sucedería en la Guerra Civil de 1891. Fundaron numerosas agrupaciones: de beneficencia y socorros mutuos, en 1882, y otras de tipo político-cultural 
como la Sociedad Dante Alighieri y la Sociedad Republicana Giuseppe Mazzini en 1892. Una de las instituciones italianas más relevantes fue la bomba Ausonia de 1874. A las anteriores debe sumárseles la Sociedad de Instrucción Italiana, que hizo un relevante aporte a la precaria instrucción pública del Iquique decimonónico, y el Colegio Don Bosco, administrado por salesianos italianos y que recibiría una considerable influencia fascista en su momento. Díaz hace hincapié en el nexo que unía a la colonia con la madre patria, expresado en la celebración de efemérides, la difusión de la cultura italiana y el aprovechamiento de toda instancia que los acercase a su país de origen (2002). Estos datos nos hablan de una sólida identidad nacional, base para el desarrollo de ulteriores posiciones nacionalistas.

Un último balance analizado, de Julio Pinto, señala, además de lo ya mencionado, los aportes de residentes italianos a las artes musicales en la ciudad y una casi homogénea composición social: sectores medios acomodados dueños de buena parte del comercio y la industria a pequeña escala en la provincia. Destaca su unidad y sus crecientes nexos con el conjunto de la comunidad regional:

\begin{abstract}
“(...) la colonia italiana de Tarapacá se fue erigiendo como una de las más cohesionadas internamente, y una de las más comprometidas con las necesidades de la comunidad regional. Esta inclinación, asociada a una posición económica que se alejaba de los sectores donde la confrontación social era más aguda, facilitó su asimilación y una cotidianeidad relativamente tranquila" (1993:88).
\end{abstract}

Esa relativa tranquilidad puede contrastarse con la actitud del movimiento obrero organizado y politizado hacia otros europeos y extranjeros en general. Normalmente los dardos se dispararon contra "el imperialismo inglés", luego "el yanqui", y sus altos empleados de la industria, rostros visibles de las contradicciones de clase del periodo salitrero. En 1892 construyeron el Círculo Italiano o Edificio Colombino, ubicado en Tarapacá y que albergó a las diversas instituciones italianas, Bomba Ausonia, Sportiva Italiania, Beneficencia y desde luego el fascio. Su incendio, en 1956, significó la pérdida de numerosas fotografías y documentos históricos, en detrimento de la memoria histórica de la colonia.
Con la chilenización compulsiva de la provincia en la década de 1910, emigraron forzosamente algunas familias ítalo-peruanas cuya residencia en Iquique databa de antes de la Guerra del Pacífico (Donoso, Ortiz, 2014). Con la crisis de 1930 no fueron pocos los italianos que abandonaron Tarapacá en el marco del despoblamiento generalizado de la provincia. Sin embargo, a diferencia de otras colonias que desaparecieron prácticamente por completo, como los alemanes y los ingleses, una cantidad considerable de italianos y sus descendientes ítalo-chilenos, permanecieron en la ciudad hasta el presente.

\section{Fascismo italiano en Chile y América Latina}

Es necesario hacer un breve balance del estado de la cuestión respecto de la influencia del fascismo italiano en Chile y América Latina. Todos los autores que han estudiado el fenómeno fascista a fondo han detectado que un gran escollo a la hora de identificar aspectos fascistas en diversos movimientos políticos del continente durante el periodo entre las dos guerras mundiales es la vulgarización del concepto por parte de la izquierda política. El Movimiento Comunista Internacional daría al concepto "fascismo" el carácter de peyorativo o epíteto negativo y lo aplicaría indiscriminadamente a toda tendencia autoritaria, anticomunista, ultranacionalista, racista o corporativista. Este uso antojadizo del concepto se extendería al conjunto de las izquierdas en toda América Latina. El siglo XX latinoamericano vio así muchos "fascismos". Estos tenían rasgos comunes con el fascismo italiano y el nacionalsocialismo alemán: el rechazo al marxismo, a la democracia liberal, a la lucha de clases, su retórica nacionalista exacerbada y sus formas políticas autoritarias o dictatoriales. En dicho saco podían caer elementos diversos: los populismos, gobiernos autoritarios conservadores e incluso las dictaduras militares de la segunda mitad del siglo XX. Sin embargo, Franco Savarino ha sido tajante en señalar que no hubo en América Latina movimientos o gobiernos que reuniesen características exactamente análogas al fascismo italiano y que entonces el uso del concepto viene siendo una "ilusión" (2008). Stanley Payne, quien ha estudiado los movimientos de tipo fascista en profundidad, enumera varias razones por las que no fue posible que en América Latina tuviesen éxito y arraigo de largo alcance movimientos históricos inspirados 
en el fascismo italiano o en el nacionalsocialismo alemán. Para Payne, los arquetipos del fascismo son modelos rígidos que solo pueden asociarse a las características de la Alemania Nazi y de la Italia Fascista y a las circunstancias históricas de ambas experiencias. Por esta razón los diversos gobiernos nacionalistas autoritarios o los movimientos políticos influenciados por ambas experiencias desde México hasta Chile tuvieron ciertas particularidades locales que los distanció de los modelos italiano y alemán, y no se pueden catalogar como fascistas (2005:104-108). No está de más señalar la existencia hasta el fin de la Segunda Guerra Mundial, en Perú, de la Unión Revolucionaria y la figura de Luis Sánchez Cerro y, en Brasil, de la Acción Integralista Brasileña comandada por Plinio Salgado, ambos notoriamente influenciados por el fascismo italiano. En la década de 1930, en el vecino país de Bolivia, hubo gobiernos populistas autoritarios denominados del "socialismo militar" quienes importaron asesores de la Italia fascista para reformar la policía y el ejército. En ese periodo los pequeños empresarios italianos residentes en el país transformaron la Sociedad de Beneficencia de Roma de La Paz en un fascio, frente a una minoría de italianos antifascistas de origen judío (Calo, 2003). La conclusión de este balance es que, si bien no hubo movimientos y gobiernos idénticos al fascismo italiano, hubo múltiples corrientes nacionalistas y gobiernos autoritarios influenciados por ciertos aspectos del fascismo italiano, y a grandes rasgos las ideas del fascismo italiano eran relativamente populares en varios países de América Latina afectados por crisis económicas y movimientos de masas en auge. La principal influencia del fascismo italiano en el extranjero fueron los fascios all'stero y organizaciones afines, de los que llegó a haber 460 fascios con 119.000 hombres, 12.000 mujeres y 40.000 jóvenes de ramas juveniles (Savarino, 2002). El primero fue el de Nueva York, fundado en 1921.

Para el caso chileno, Jorge Rojas Flores enumera una larga lista de personajes destacados de la política, la diplomacia, las fuerzas armadas y la Iglesia católica, junto con varias publicaciones, que simpatizaban abiertamente con el modelo fascista italiano. El punto en común de todos era el corporativismo como solución a la lucha de clases que recrudeció en Chile a raíz de la crisis endémica en que se sumió la industria salitrera tras la Primera Guerra Mundial. Entre todos estos personajes que en su momento mostraron simpatías por la Italia fascista se cuentan tres presidentes de la república: Carlos Ibáñez del Campo, Eduardo Frei Montalva y Arturo Alessandri Palma. Frei y Alessandri posteriormente renegarían de dichas simpatías, sin embargo, el primero incorporaría la idea fascista de un tercer modelo, alternativo al socialismo marxista y al capitalismo liberal, al ideario de la Democracia Cristiana. Este partido, posteriormente, reciclaría en sus filas a numerosos exsimpatizantes del fascismo y del nacionalsocialismo. En 1929 Ibáñez dispuso la creación de instituciones semicorporativas que agrupasen a empresarios y obreros y designó una comisión para diseñar estas instancias. La comisión estaba compuesta, entre otros, por Armando Labra, exsecretario de la embajada en Italia y uno de los primeros y más entusiastas difusores de fascismo italiano en Chile (Rojas, 1993: 46-59). Alessandri era particularmente apreciado por la colonia italiana como descendiente de italianos en la jefatura del Estado, motivo de orgullo para la colonia. Esta influencia del fascismo italiano es clave para comprender la existencia de los fascios all'stero en Chile. Estos surgieron en momentos en que un sector considerable de la opinión pública chilena veía con interés el modelo italiano y consideraba ciertos elementos para su implementación en Chile. Esto permitió a la colonia italiana manifestar su adhesión al fascismo y crear orgánicas afines, los fascios, con relativa normalidad, siendo concurridas sus actividades por intendentes, alcaldes, autoridades eclesiásticas y militares. Por otra parte, en la década de 1920 y 1930 numerosos italianos destacados en el ámbito de las artes, la cultura, la arquitectura, la teología y otros campos, emigraron a Chile trayendo consigo influencias fascistas (Maldini, 2004). En 1924 el barco Italia recorrió América Latina con una delegación de hombres de ciencia y cultura que exponían a los visitantes los logros y el progreso de la nueva Italia fascista, siendo recibidos con mucho interés por la opinión pública y con renovado fervor nacionalista por las colonias italianas de Chile. En octubre de 1928 el comandante de la Baquedano visitó a Benito Mussolini a nombre de la Armada de Chile. En dicha ocasión el embajador de Chile en Roma señaló que la visita sería: "una prueba creciente del interés que demuestra Chile, como igualmente otros países latinoamericanos, que miran el magnífico progreso de la Italia fascista. Existen muchos puntos comunes entre los gobiernos de Roma y Santiago o el derecho de la autoridad del Estado 
frente a la desintegración del parlamentarismo"1. Existía en Chile un interés generalizado por la Italia fascista, lo que deriva en una curiosidad benevolente y una amplia tolerancia para con los italianos que manifestaron su adhesión al fascismo en suelo chileno y crearon orgánicas, en teoría extensiones del Partido Nazionale Fascista de Italia, PNF. En Chile la primera de estas organizaciones, el Fascio de Valparaíso, se constituyó en junio de 1923. En dicha ciudad los italianos formaban una gran colonia que incluso tenía un órgano de prensa: L'Italia (Schafeld, 2005). Surgieron de forma casi espontánea, debiendo el régimen italiano darles orientaciones y estatutos posteriormente a su constitución.

\section{Colonia Italiana y fascismo en Iquique}

\begin{abstract}
"A las 9 de la mañana se encontraron en el local colombino las diversas instituciones italianas, reduci de la guerra, fascistas, miembros de la Sociedad de Beneficencia y Bomba Ausonia. En correcta formación el cortejo se dirigió al Templo Salesiano, donde se había preparado un hermoso catafalco en la nave central, con grandes colgaduras negras y adornos de palmeras y coronas. Al llegar al recinto sagrado, los fascistas y reduci de la Guerra hicieron el saludo fascista, en memoria de aquellos que cayeron combatiendo por la patria". El Tarapacá, Iquique, 5 de noviembre de 1927.
\end{abstract}

La información recién citada corresponde a la primera aparición pública del fascismo de la colonia italiana que pudimos encontrar, casi 4 años después de la conformación del fascio de Valparaíso. El 4 de noviembre será la principal efeméride del calendario italiano. Junto con celebrar la victoria de las armas italianas en Vittorio Venetto, se celebraba la Marcha sobre Roma, despliegue de fuerza con el que Mussolini se hizo del poder en Italia. Para la narrativa histórica del fascismo, la Marcha sobre Roma era la coronación de la victoria de Venneto. Hernán Ramírez Necochea, en su documento El Fascismo en la evolución política de Chile menciona la fundación a partir de la Liga Patriótica de Iquique, de un pequeño y efímero Partido Fascista, imitación del modelo italiano (1978). Esta oración ha sido citada en más de una ocasión sin que los investigadores se hayan molestado en corroborar su veracidad o exactitud, ya que no se han detectado mayores referencias y fuentes al respecto. Es posible que, en realidad, Necochea esté confundiendo una supuesta organización fascista de corte italiana con el surgimiento del fascio de la colonia italiana residente. La aparición del fascio se caracterizó por traer a las calles de Iquique y a los centros de reunión de la colonia italiana elementos rituales similares a los implementados en la madre patria: uniformes, saludo romano y ornamentaciones afines. "El local colombino" al que se alude es el edificio mencionado indistintamente como Edificio Colombino o Círculo italiano, ubicado en calle Tarapacá. El Templo Salesiano es la Iglesia del Colegio Don Bosco, donde impartían la enseñanza desde 1893 sacerdotes italianos salesianos con un contenido italianizante. En dicho colegio se adoptó por un tiempo incluso formas de reminiscencia fascista en materia de uniformes e himnos. La música del famoso himno fascista la Giovinezza fue adoptada con himno de la institución con la letra cambiada. A la iglesia del colegio Don Bosco iban los fieles católicos italianos, y al colegio asistían sus hijos, parte de la elite de la ciudad. Uno de nuestros entrevistados, Mikele Manielo Evangelista, fue claro en la relación Iglesia, catolicismo y fascismo. A pesar de lo complejas que fueron las relaciones entre Iglesia y fascismo en Italia, en Iquique, la religión, y no la condición socioeconómica, fue una de las piedras de toque entre fascismo y antifascismo. Los inmigrantes católicos, la mayoría, adhirieron al fascismo. Por otra parte, los masones fueron antifascistas y republicanos, pero minoritarios. Esta identidad entre religión e ideología se afianzó con la firma del Tratado de Letrán en 1929. Mikele Manielo, quien a veces castellaniza su nombre como Miguel, tiene 82 años y es hijo de un reduci italiano, es decir, veterano de la Primera Guerra Mundial, emigrado de Italia a Iquique tras el fin de la guerra. La historia de su padre es la historia de varios de los miembros del fascio de Iquique (Fotografía 1). Benedeto Manielo Saruzi (1898, Palmira- 1973, Iquique) combatió en caballería, infantería y artillería, tomando parte en la batalla de Vittorio Véneto, en donde Italia infringió una derrota definitiva al Imperio Austro-Húngaro. Hombre conservador, pequeño comerciante, dueño de un almacén de abarrotes y herramientas, católico y veterano de guerra ${ }^{2}$. Benedeto Manielo fue el prototipo de sujeto que integró el fascismo en la Italia post-Primera Guerra Mundial: su condición social lo lleva a rechazar toda clase de perturbaciones 


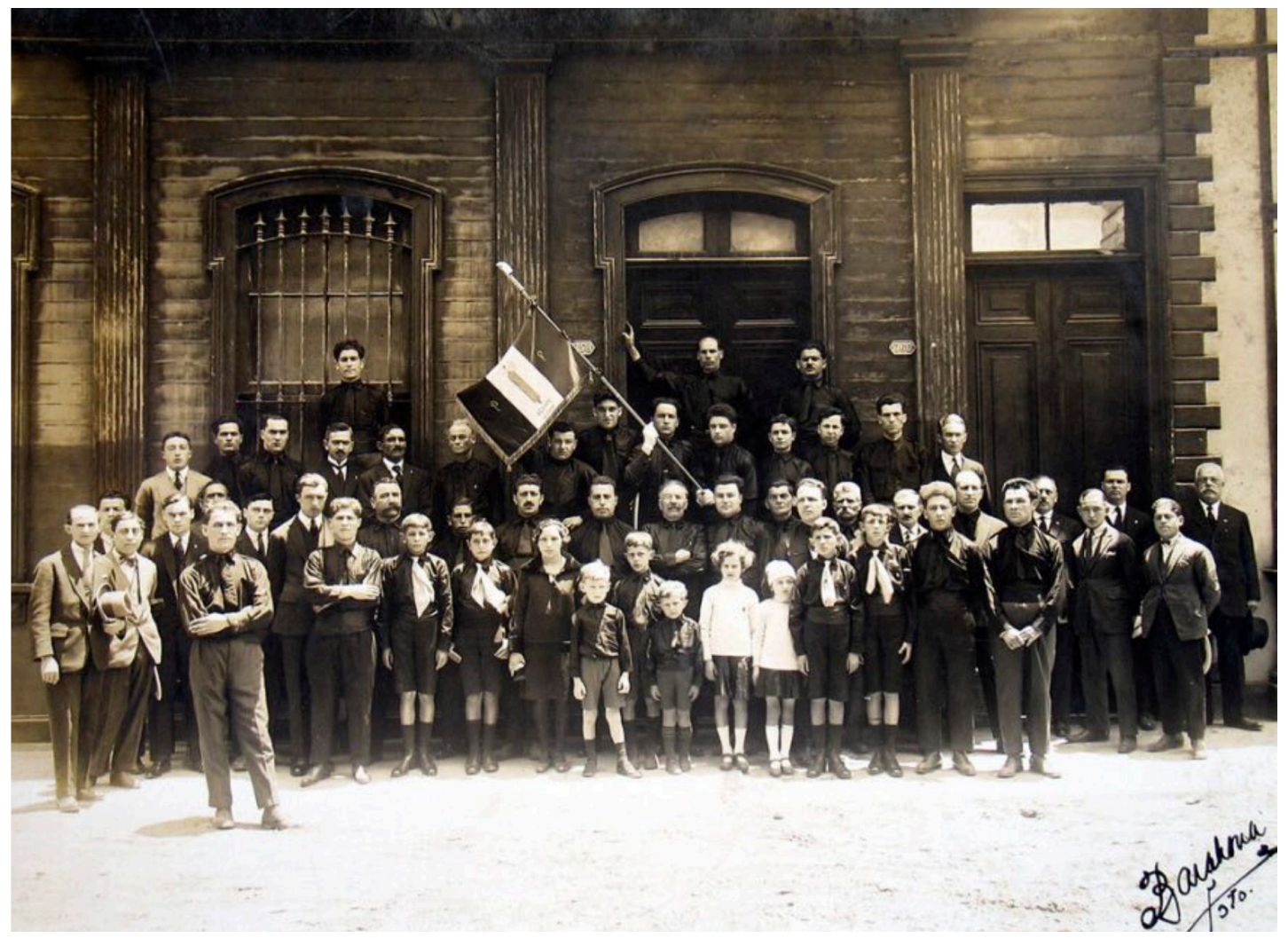

Fotografía 1. El fascio de Iquique, sin fecha, posiblemente década de 1930. Fotografía propiedad de la familia Canessa, facilitada para esta investigación por Vittorio Canessa, nieto de Humberto Canessa, miembro del fascio. Destaca la bandera fascista, los hombres con camisas negras, niños balilla y jóvenes avanguardistas.

sociales asociadas al comunismo o anarquismo, y su condición de veterano lo llevó a simpatizar con las reivindicaciones nacionalistas del fascismo en torno a la "victoria mutilada" de Italia en la Primera Guerra Mundial. Caso similar al de Benedeto Manielo es el de Luis Be, miembro del fascio que también era presidente de los reduci radicados en Iquique organizados en la Asociación Nacional de Combatientes y era, además, presidente de la Beneficencia Italiana.

La aparición pública del fascismo italiano en la ciudad de Iquique coincide con un periodo en que se difundieron en la prensa local fuertes atisbos de cercanía entre la dictadura de Carlos Ibáñez del Campo y la Italia fascista. Además, el otrora numeroso Partido Comunista de Chile, $\mathrm{PC}$, su principal detractor, se hallaba proscrito y disperso. El fascio continuó haciéndose notar públicamente al año siguiente, 1928. Con motivo de la prohibición de la prensa comunista y anarquista por parte del régimen de Ibáñez, algunos periodistas vinculados a dicha prensa debieron refugiarse en otras publicaciones. Tal fue el caso de Esteban Marré, quien paso del clausurado El Despertar de los Trabajadores, al moderado La Provincia. El 29 de octubre de 1931, La Provincia publicó, de la mano de Marré, un artículo condenando y criticando en duros términos a los regímenes de Primo de Rivera en España y de Benito Mussolini en Italia ${ }^{3}$. El fascio replicó calificando las publicaciones como "propias de un cerebro descarriado" y añadiendo:

"escriben solamente contra el gobierno de Italia y España, porque no tienen audacia bastante para hacerlo en contra del Gobierno chileno y de su Excelencia Carlos Ibáñez. Es suficiente conversar un poco con los italianos recientemente llegados de Italia (entre los cuales hay antiguos y conocidos comerciantes, por supuesto alejados de la política) para convencerse del desequilibrio 
del artífice de calumnias e injurias contra un gobierno cuya política de saneamiento y restauración tanto se asemeja con la del gobierno chileno"4.

Al día siguiente, apareció otra nota de prensa en la que las diversas organizaciones de la colonia italiana daban su apoyo al fascio de Iquique y condenaban publicaciones contrarias al gobierno italiano. Firmaban la Asociación Nacional de Combatientes, la Sociedad Sportiva Italiana, la Sociedad de Beneficencia y la Bomba Ausonia. Este hecho demuestra un fenómeno de tres dimensiones en torno al fascismo italiano en el exterior: el fascismo es en principio una posición política e ideológica, pero comenzará a asociarse con el ser italiano, en tanto identidad nacional, y con ser italiano con participación en las organizaciones de la colonia. Se constituyó así una triple identificación entre comunidad socialmente organizada, nacionalidad e ideología. Esta triple identidad se manifestará en otros factores como los aportes en oro a las arcas fiscales del Estado italiano por parte de las organizaciones italianas a la política imperialista de Mussolini, y el hecho de que los dirigentes de las organizaciones italianas y miembros del fascio serán normalmente las mismas personas.

\section{3-1936: los años de mayor visibilidad del fascismo italiano en Iquique}

La década de 1930, hasta la constitución del Frente Popular, fueron años de auge de la actividad fascista en Iquique. La presencia de un nuevo cónsul real en la ciudad, Víctor Mongillo, fue un factor que reforzó el carácter fascista que estaba adquiriendo, al menos en lo formal, la colonia italiana residente. Diplomático de carrera, sustituyó al antiguo cónsul honorario Antonio Brazzale, quien también fue un entusiasta fascista. Mongillo fue descrito por otro entrevistado, Ernesto Gandolfo, de 93 años, como un activista fascista convencido que andaba cotidianamente uniformado con su camisa negra. Las actividades públicas altamente concurridas, la identificación cuasi plena de la colonia con el régimen de la madre patria y el reforzado vínculo con Italia fueron características de estos años.

El año 1933 fue particularmente prolijo en actividades de cierta envergadura y alto impacto en la opinión pública local. Entre las principales actividades de los fascios all'stero estaba la difusión de informaciones de actualidad que realzaran el prestigio del régimen fascista junto con una destacada labor de carácter cultural en torno a las efemérides nacionales italianas: la unificación de Italia, el 20 de septiembre, la Marcha sobre Roma, la última semana de octubre y la firma del armisticio que puso fin a la Primera Guerra Mundial el 4 de noviembre. Los fascios no actuaban en esta tarea solos, normalmente se apoyaban en otras organizaciones, por ejemplo las sociedades Dante Alighieri, existentes en todo el mundo donde hubiesen colonias italianas. En Iquique existía una que fue disuelta con motivo de la ruptura de relaciones diplomáticas entre Italia y Chile, en enero de 1943. En octubre de 1933 la prensa dio a conocer algunas informaciones y noticias que hablan de una intensa actividad. El 30 de enero de ese año, Hitler había sido nombrado canciller en Alemania provocando un júbilo en el fascio local, que consideró que la doctrina del fascismo avanzaba todopoderosa a la conquista del mundo:

"Hoy día el fascismo ha cruzado los Alpes y su doctrina constructora anima a los patriotas de todas las naciones. En Alemania (...) florecen las industrias y las artes, domina la ciencia. El fascismo, con Hitler a la cabeza, edifica y reconstruye. Edificando y reconstruyendo tiende la diestra amistosa a los que fueron sus enemigos de ayer en un afán de fraternidad y de paz que ha de regenerar al mundo. ¡Oh salve Italia fascista y salve a ti Germania, indispensable al resurgimiento económico de la pobre y aporreada humanidad y al equilibrio de Europa! A. NOI. Iquique, octubre 28 de $1933 " 5$.

Sin embargo, no todos aceptarían de buena gana esta creciente "fascistización". En 1933 aconteció el primer acto de rechazo a las actividades de carácter fascista de la colonia italiana iquiqueña. A modo de introducción a las grandes celebraciones que tendrían lugar con motivo del aniversario del armisticio en noviembre de 1933, la Sociedad Nacional Dante Alighieri-Comitatto Iquique organizó una velada en el desaparecido Teatro Arauco, dependiente del colegio Don Bosco. Esta sociedad, si bien databa de antes del fascismo, durante el periodo de Mussolini sirvió como vehículo de difusión cultural del fascismo. La velada consistía en una exhibición de una 
película de propaganda que enseñaba el desarrollo de Italia bajo el fascismo. A la velada asistió, además del fascio, numeroso público incluyendo supuestos elementos del Movimiento Nacional Socialista, MNS, que había fundado una célula y un periódico en Iquique, apoyado por personajes de la colonia alemana residente. El Partido Comunista, PC, y su Federación Obrera de Chile, FOCH, habían reaparecido en la ciudad tras la caída de Ibáñez. Fuertemente integrado al Movimiento Comunista Internacional, tras la "bolchevización" apoyada por agentes de la Tercera Internacional, el PC esgrimía un enérgico discurso antifascista. Llevando el "internacionalismo proletario", es decir, la solidaridad con el perseguido Partido Comunista de Italia y los comunistas presos políticos, a los hechos, se hicieron presentes fuera del Teatro Arauco:

"Conocido esto por algunos obreros y como un gesto de solidaridad con el proletariado italiano que sufre el efecto de la feroz dictadura mussoliniana. Realizaron una manifestación antifascista frente al Teatro Arauco a la salida de la función. (...) se oían entre otros gritos ¡Muera el perro Mussolini! ¡A Abajo el asesino Hitler! ¡Abajo el fascismo y el nazismo! y otras tantas cosas más lo que dio motivo a incidentes entre los fascistas italianos, a los cuales se agregaron nacistas chilenos y los obreros antifascistas. En la pelea que hubo, pues se fueron a las manos y se atacaron a pedradas, se llevaron la peor parte los fascistas italianos, quienes fueron alcanzados por los golpes de los obreros antifascistas quienes quedaron dueños del campo realizando un desfile por calle Vivar al son de gritos y vivas al proletariado italiano. Este hecho ha producido un gran alboroto entre los italianos pobres residentes en esta provincia que repudian a Mussolini, Turatti y Cía. y que han conocido en forma efectiva el modo de proceder de los fascistas en Italia. Esta manifestación antifascista marca la era de una seria lucha ya no solo contra las demostraciones del fascismo italiano, sino que también contra los "nacistas" criollos que pretenden hacer la misma gracia de Hitler en Alemania, Mussolini en Italia y Pilsudky en Polonia"'6.
La colonia italiana y su componente fascista dejaron su versión de los hechos en El Tarapacá, que en la práctica fue su tribuna durante el periodo estudiado:

"Para los amigos y enemigos del régimen imperante en la península, la función que tuvo lugar en el Teatro Arauco debía resultar de grandísimo interés pues con pruebas fehacientes se demuestra lo que pueden la disciplina y el orden para el adelanto de un país. Pero así no lo han comprendido los comunistas, que se preconizan como reformadores del Estado y un grupo de esta gente inconsciente, con una provocación que habla muy en contra de la cultura de estos profetas de la anarquía, esperando con premeditada maldad la salida del público han gritado con voz destemplada ¡abajo Mussolini! ¡Abajo el fascismo! Vitoreando a su partido que está al margen de toda ley sensata. Y no se han limitado a gritar, sino que han asaltado a los pacíficos asistentes al acto cultural, siendo repelidos valientemente por el joven fascista Luis Ferreto que ha quedado herido en la región parietal derecha"?.

Luis Ferreto era hijo del capitán de ejército italiano y reduci radicado en Iquique del mismo nombre, quien a su vez era miembro del directorio del fascio, caso parecido al de Benedeto Manielo. No existe parte de policía de este enfrentamiento ni personas vivas que lo puedan recordar, de modo que estas dos notas de prensa, de diarios políticamente opuestos, el comunista Justicia y el derechista profascista El Tarapacá, son las únicas dos fuentes para este hecho que marca la llegada a las calles de la ciudad del gran enfrentamiento ideológico y político que dividió al mundo en el periodo. Llama la atención la mención que hace Justicia a la existencia en la provincia de supuestos italianos pobres antifascistas. Los autores que han tratado la inmigración italiana a Tarapacá coinciden en homogeneizar socialmente a la colonia italiana en tanto pequeños y medianos empresarios, es decir, pequeña burguesía. Es posible que más de alguno se haya arruinado con la crisis de 1930, cuyos efectos deprimieron la economía regional por décadas. Sin embargo, parece poco plausible hablar de un segmento social de italianos proletarizados o pauperizados que 
tuviesen inclinaciones antifascistas. Nos parece más razonable reiterar lo señalado por la única fuente clara al respecto. Mikele Manielo enumera a varias familias italianas vinculadas a la masonería que fueron antifascistas y que en el periodo aludido no participaban de las actividades oficiales del sector profascista mayoritario de la colonia. Manielo recuerda algunos: la familia Cesarego. Silvio Fígalo, dueño de una fábrica de gaseosas y fideos y Francisco Lázala, dueño de la Panadería Italiana fueron elementos de la colonia italiana miembros de la masonería y antifascistas ${ }^{8}$. Tienen como antecedente en la provincia la Sociedad Republicana Giuseppe Mazzini, que funcionó en Iquique hacia fines del siglo XIX y estaba conformada por italianos y chilenos que promovían un pensamiento liberal avanzado y republicano, asociado a la masonería, frente a una inmigración italiana mayoritariamente conservadora, católica y monárquica. La tendencia antifascista fue claramente minoritaria. En Iquique no se observó el fenómeno de fractura de las colonias italianas con la irrupción del fascismo ocurrido en otros países como Argentina, EE.UU. y México, que recibieron una gran inmigración de carácter proletaria y de tendencias socialistas, anarquistas y comunistas (Savarino, 2002, Fanesi, 1994). En aquel periodo predominaba una línea ultraobrerista en el Movimiento Comunista Internacional y es posible que Justicia haya preferido hablar de italianos pobres en vez de una pequeña burguesía masónica y antifascista. Estas muestras de repudio contra las actividades públicas del fascismo italiano, que eran en el fondo el repudio a la existencia misma de una corriente fascista en la ciudad, fueron las que en el fondo terminaron con la existencia pública del fascismo hacia fines de la década. El PC no dejaría de hostilizar públicamente a los fascistas italianos residentes y con el desarrollo del Frente Popular dicho repudio crecería abarcando gran parte del espectro político. Como señalamos, el periódico El Tarapacá fue un entusiasta vocero del fascismo italiano en la provincia, particularmente durante la administración de Alberto Brandan y posteriormente la de Eduardo Frei, 1935-1936. Recién con Radomiro Tomic en la dirección, ya finalizando la década de 1930, el periódico empezaría a apartarse de sus simpatías profascistas para terminar comprometido con la causa aliada durante la Segunda Guerra Mundial.

Hacia 1933, el directorio del fascio estaba compuesto por las siguientes personas, en la Fotografía 2 de izquierda a derecha: Gerardo Corbo, Francisco Vassallo, Domingo Monguillo, Luis Ferreto y Alfredo Macchiavello9. Todos miembros de distinguidas familias de la colonia italiana, dirigidos por el real cónsul Domingo Monguillo, que ostentaba el cargo máximo de secretario del fascio.

El sábado 4 de noviembre de 1933 El Tarapacá dedicó una edición especial de homenaje a la Italia fascista. Los representantes del fascio se tomaron

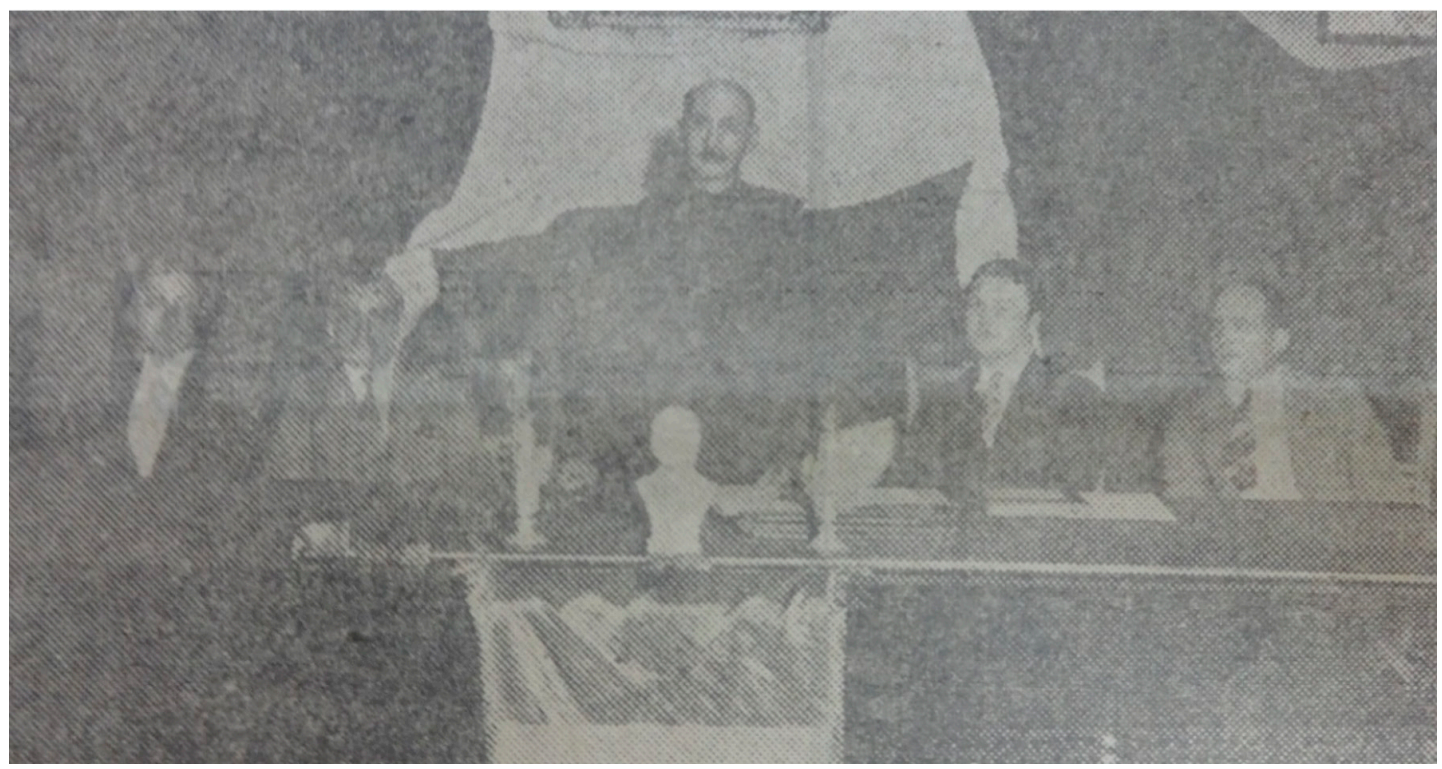

Fotografía 2. Directorio del fascio en Iquique. Fuente: El Tarapacá, 4 de noviembre de 1933. 
las páginas del diario para escribir largos artículos y poemas laudatorios al fascismo y a la figura de Benito Mussolini junto con artículos acerca de la actualidad italiana. Las celebraciones del 4 de noviembre fueron particularmente ostentosas y de marcado contenido fascista, en contraste con los años anteriores en que fueron más modestas en relación con el estado general de crisis económica en que se encontraba la provincia. En aquella ocasión las actividades de la colonia fueron visitadas por los altos mandos militares de la provincia, del clero, del gobierno y del municipio. Monguillo con el uniforme negro del PNF inició su largo discurso saludando a las autoridades presentes: alcalde Enrique Brenner, intendente Orlando Villablanca, gobernador marítimo Armando Mora y comandante de la guarnición del ejército y representantes de las otras colonias.

Los años de la guerra de Abisinia fueron los últimos de actividad pública de la colonia italiana y sus expresiones fascistas. En aquel periodo los representantes de la colonia asumieron plenamente el discurso colonial y racista que justificó la agresión de Italia a Etiopía: la necesidad de dar a los italianos un imperio colonial en donde trabajar y prosperar, y a su vez llevar a la civilización, cual antigua Roma, a pueblos atrasados y esclavizados. Con motivo de las celebraciones del 4 de noviembre de 1935, el secretario del fascio iquiqueño, cónsul Mongillo, señaló:

"Tierras, que aún hoy en día, hoy son habitadas por una mezcla de poblaciones semi salvajes, que solo conocen la ley del más fuerte, que no saben aún de esos privilegios que han hecho del hombre el ser superior de la naturaleza. Poblaciones que desde hace varios años están sometidas al yugo de una autoridad barbárica, cuyo dominio solo sabe manifestarse en la cobranza de tributos por medio de la fuerza, y con su protección complaciente en favorecer la esclavitud, como una de sus principales fuentes de recursos. En estas tierras aún esperan los beneficios de la civilización moderna, quiere Italia aportar la luz de Roma y su civilización en una ordenada y próbida obra de colonización. Se acusa a Italia de proceder arbitrariamente con Abisinia valiéndose de la ley del más fuerte. ¡Nada más injusto!”10.
En noviembre de 1936, en la Iglesia de los Sagrados Corazones, llamada a veces "de los salesianos" se celebró una misa por los caídos en la guerra de Etiopía a la que asistió el fascio con Mongillo a la cabeza, los bomberos de la Ausonia, los reduci y la colonia en su conjunto. Posteriormente Monguillo leyó un mensaje de Piero Parini, ministro de relaciones exteriores del régimen fascista, saludando la unidad de las colonias con la madre patria, la belleza del naciente imperio colonial y asegurando que el fascismo daría trabajo a todos los italianos que se habían visto forzados a emigrar. Por último los exhortó a mantenerse fieles y serenos ante las fuerzas de la barbarie y el caos ${ }^{11}$. Estas últimas eran, sin duda, las izquierdas en la incipiente Guerra Civil Española y en varios lugares del mundo, incluido Chile, donde registraban avances y crecimiento electoral. Italianos de todo el mundo donaron oro y plata a las arcas fiscales italianas para sostener el esfuerzo bélico colonial en todo el mundo. En Iquique la colonia no se quedó atrás, las diversas organizaciones italianas aportaron las siguientes cantidades de oro y plata:

"Asociación Nacional de Ex Combatientes: 150 gramos de oro y 57 de plata. Entre los miembros de la Compañía de Bomberos Ausonia varias medallas con 561,7 gramos de oro y 149,5 de plata; entre varios miembros de la colectividad italiana grs.761,5 de oro y 148,5 de plata, además una targa de 114 grs. obsequiada por la Sociedad Sportiva Italiana. En resumen son: 1.562.9 grs. de oro y 355,4 de plata" ${ }^{12}$.

Este donativo fue la única acción concreta llevada a cabo por la colonia italiana. Los fascistas no se mencionan porque formaban parte de todas las organizaciones italianas. De Valparaíso partieron algunos jóvenes fascistas a luchar en la aventura imperialista de su madre patria. Sin embargo ninguno de Iquique, situación que contrasta con el entusiasmo desatado por la Primera Guerra Mundial en la que combatieron varios italianos radicados en Iquique. Esto nos retrotrae a una cuestión fundamental que permite evaluar el grado de profundidad que tenía la influencia fascista en la colonia italiana de Iquique.

¿Cuál era la función de los fascios all'stero y las organizaciones de carácter fascista en el extranjero? Al principio su función y orgánica no era muy clara. En parte obedecían a un secretariado de fascios en 
el exterior del Partido Nacional Fascista y en parte debían coordinarse con las representaciones diplomáticas oficiales de Italia en cada país, dependientes del Ministerio de Relaciones Exteriores. Es decir, eran organizaciones dependientes de Italia. En 1928, Mussolini dictó las 8 normas de los fascios all'stero. Las dos primeras hacían hincapié en no inmiscuirse en la política del país anfitrión y respetar las leyes de este. Las demás tenían que ver con obediencia a los representantes de Italia, rectitud moral y solidaridad con los connacionales. En síntesis, tomando en cuenta las primeras disposiciones para los fascios all'stero aparecidas en 1922 y las normas definitivas dadas por Mussolini, los fascios eran organizaciones de cohesión de las colonias italianas bajo el fascismo, de difusión de la italianidad entendida como unidad cultural y nacional con el fascismo (Savarino, 2002). Debían esperar con lealtad y fidelidad el triunfo del fascismo y de su política exterior, que traería bienestar a los italianos repartidos por todo el mundo. Precisamente esa fue la labor de los fascistas italianos durante sus años de actividad en Iquique. Las conmemoraciones patrióticas, realzar el prestigio de la colonia, renovar el nacionalismo y la identidad cultural e informar a la comunidad de Iquique de los logros del régimen italiano.

\section{El ocaso de una época: el fin del fascismo y de las actividades públicas de la colonia italiana de Iquique}

Un último testimonio tomado nos llamó la atención por un elemento. Ernesto Gandolfo es un empresario italiano residente en Iquique que emigró en 1938 desde Italia por razones económicas a Iquique, donde vivían unos tíos comerciantes. Él venía de haber vivido toda la experiencia juvenil fascista como niño balilla y adolecente avanguardista, formaciones juveniles del Partido Nacional Fascista. Sin embargo al momento de su llegada, según su recuerdo, ya no era evidente la adhesión fascista de parte de los miembros de la colonia ni de sus propios familiares ${ }^{13}$. Había comenzado cierta desafección, al menos pública, por parte de los italianos residentes hacia el fascismo. Las razones de este proceso de "desfascistización" son varias, pero la principal fue la creciente hostilidad de gran parte de la sociedad chilena, representada por el Frente Popular, hacia las expresiones de "fascismo", ya sea en su significado más puro como en generalizaciones vulgarizadas. Iquique fue escenario de multitudinarias marchas de los partidos del Frente Popular con contenido antifascista, que exigían la ruptura de relaciones con el Eje y medidas de vigilancia para los ciudadanos de dichos países. Los alcaldes comunistas del periodo, Eloy Ramírez y René Reyes, a diferencia de sus predecesores Alfonso Echeverría y Enrique Brenner, fueron declarados antifascistas y ellos mismos respaldaron este movimiento de masas a favor de los aliados en la ciudad, particularmente desde la invasión del Eje a la URSS. Estas manifestaciones recorrían Iquique, terminando en Plaza Condell, y exigían purgar el país de "nazi-fascistas" extranjeros y "quintacolumnistas" nacionales y fijar precios a los artículos de primera necesidad. Lucían carteles del "presidente de los Estados Unidos, señor Delano Roosevelt y de don José Stalin, asimismo, se lucían algunos motes alusivos al acto que decían: abajo el nazi-fascismo, mueran los especuladores, vivan las democracias" 14 . Otro comicio masivo, auspiciado por la alianza de partidos de izquierda denominada "Unión para la Victoria" y la Confederación de Trabajadores de Chile, CTCH, exigía "clausura de los diarios, revistas, agencias y clubes regentados por súbditos de países del Eje, que desarrollan actividades contrarias a nuestro país. Medidas drásticas e inhabilitación para comerciar a elementos fascistas extranjeros que se hayan distinguido por actividades sediciosas en beneficio de los países totalitarios"15. La posibilidad de que se repitiesen escenas como la gresca callejera del Teatro Arauco estaba mucho más latente. Incluso, el diario El Tarapacá le dio la espalda al fascismo italiano pasando de alabarlo a repudiarlo. Este diario moderó brevemente su acérrimo anticomunismo como política unitaria hacia el PC y la URSS. Con el estallido de la Segunda Guerra Mundial las colonias de países agredidos por el eje y sus simpatizantes iniciaron un boicot contra el comercio italiano. Mikele Manielo recuerda que los productos del comercio mayorista británico eran negados a los pequeños negocios italianos como es el caso del negocio de abarrotes de su padre, Benedetto Manielo ${ }^{16}$. Solo las firmas alemanas, como Gildemeister, siguieron comerciando con los italianos.

En febrero y marzo de 1943 llegaron a Tarapacá las instrucciones del ministerio del interior para conculcar el porte de armas o negar el permiso para ello a todos los ciudadanos del eje y luego la prohibición de izar los pabellones de dichos países ${ }^{17}$. En el periodo previo a la ruptura, el ultranacionalismo que caracterizó a la colonia italiana durante los años 
del fascismo fue reemplazado por un pragmatismo y adaptabilidad que se tradujo en la apresurada solicitud de nacionalidad chilena de varios miembros de la colonia: Lancelloti, Arna y otros, posiblemente previendo las dificultades que traería la creciente presión interna y externa sobre el gobierno de Juan Antonio Ríos para pasar definitivamente al bando aliado $^{18}$. El descubrimiento reciente de una red de espías del eje conformada por ciudadanos alemanes y un italiano que abarcaba del extremo sur de Chile hasta Iquique complicaron aún más la situación. Los primeros meses tras la ruptura, conocidos ciudadanos alemanes de Iquique, y un japonés avecindado en Arica, fueron relegados a Pica y Pisagua. Los intereses de los italianos quedaron representados por el consulado de la España franquista. Mikele Manielo no recuerda con exactitud la fecha, pero en ese periodo se disolvió el fascio y la Sociedad Nacional Dante Alighiero-Comitatto Iquique. Su biblioteca fue distribuida entre miembros de la colonia, quedando libros y folletos de propaganda fascista en manos de las distintas familias italianas de la ciudad ${ }^{19}$.

La infancia construyó su propia guerra imaginaria en las calles de Iquique, cuando las piedras se convirtieron en balas en la mente de los muchachos pertenecientes a una u otra colonia. Mikele Manielo recuerda cómo los niños de la colonia británica, y otros simpatizantes de los aliados se enfrentaban a pedradas en los alrededores del colegio Don Bosco con los muchachos de la colonia italiana. Batallas en las que él mismo participó siendo muy niño y sin comprender en profundidad lo que acontecía en Europa. Recuerda que en ese entonces la asociatividad italiana se volvió cerrada y privada. Su padre, aficionado a la radiotransmisión, junto con sus amigos, se reunía a oír y comentar las noticias del frente en las tardes. De Iquique partieron una joven y dos jóvenes de origen británico a combatir a Europa ${ }^{20}$, sin embargo la colonia italiana quedó sumida en la mayor inmovilidad y silencio. Esta actitud perduraría incluso hasta la postguerra. Manielo señala que pasaron años tras 1945 para que la colonia italiana volviese a organizar actividades públicas, desprovistas ya de todo contenido fascista. La rápida "desfascistización", e incluso parcial chilenización, de parte de la colonia permitió a los italianos proseguir sus vidas normales sin mayores problemas. Esto no implicó que la colonia italiana se tornase antifascista, más bien se trató simplemente de olvidar y dejar atrás la adhesión al fascismo para preservar su posición social y tranquilidad. Muchos de ellos se hundieron en la profunda angustia de tener familiares en Italia en medio de la violencia de la doble guerra: civil entra partisanos y fascistas, y mundial, entre los aliados y el eje. Es el caso de Ernesto Gandolfo, quien relata haber sufrido mucho por el permanente peligro y la extrema miseria que atravesaron sus padres y familiares italianos en Europa. Sin embargo aún sostiene que: "Lo que le hicieron a Mussolini fue un crimen horrible, una barbaridad. Lo colgaron como un cerdo, la mayor denigración. ¿Acaso no habían derechos humanos para él?" 21 . La afirmación de Gandolfo refleja, en nuestra opinión, la posible opinión de un sector de la colonia que hubiese deseado que el régimen fascista y Mussolini no llegasen al final que llegaron cuando el duce, su amante y colaboradores. fueron ejecutados y colgados en la plaza de Milán por partisanos comunistas.

\section{Conclusiones}

El duce de Iquique, Domingo Monguillo, falleció en Iquique en 1943. Su velorio se realizó de forma muy discreta y sin la parafernalia fascista que caracterizó las actividades italianas al menos hasta 1937. ¿Cómo fue que la colonia abandonó el fascismo tan rápidamente y llevó una vida relativamente tranquila durante la guerra? Ningún italiano de Iquique fue relegado ni procesado por actividades subversivas. El fascismo y el vínculo militante con la madre patria no habían sido tan profundos como en el caso de los alemanes nazis residentes en Chile, que organizaron un complejo y subterráneo intento de influenciar a la sociedad chilena y utilizar Chile como base de espionaje. Esta adhesión superficial al fascismo tiene algunas explicaciones desarrolladas por otros autores que han investigado el fenómeno del fascismo italiano en otros puntos de América Latina. La adhesión al fascismo en forma de rituales, uniformes, iconografía, gestos, etc., no implicó una profunda comprensión política y teórica de la doctrina fascista, doctrina que en sí misma tuvo postulados confusos que fueron definiéndose con el tiempo. En más de una ocasión, dirigentes del PNF expresaron su preocupación al percibir una "fascistización" parcial de los italianos en el extranjero, más cercana a la pasión momentánea que a la profunda convicción ideológica. Giuseppe Manielo, de 79 años, el hermano menor de Mikele Manielo, hace hincapié en lo mismo: "se 
admiraban las obras del gobierno italiano porque se pensaba que mejoraban el país cuando había mucha cesantía, eso daba un orgullo nacional que no era una cosa de conocimientos políticos"22. Cuando el contexto político se tornó difícil para manifestarse públicamente como fascista, los italianos residentes no tuvieron mayores contradicciones personales en abandonar las formas y discurso fascistas.

Otro factor que explica la rápida "desfascistización" de la colonia italiana residente dice relación con la posición socioeconómica adquirida con mucho esfuerzo tras décadas de residencia en la ciudad. Negocios, talleres, fábricas, todo levantado a pulso desde pequeños capitales, rememorando los lugares comunes de la mística del esfuerzo capitalista. Una aventura política o pasiones nacionalistas e ideológicas no eran motivos suficientes para arriesgar la comodidad adquirida con largos años de trabajo. Este factor que explica, en parte, la "desfascistización" de la colonia italiana de Buenos Aires, es también aplicable al caso iquiqueño (Cortese, 2011).

Durante los años que existió una influencia fascista en la colonia italiana de Iquique, se manifestó un renovado orgullo nacionalista, cuya máxima expresión fueron las fastuosas conmemoraciones del 4 de noviembre y otras actividades desarrolladas en el periodo. Sin embargo fue un fenómeno relativamente superficial que no trascendió más allá de la Segunda Guerra Mundial y que tendió a desaparecer rápidamente cuando el entorno se puso hostil.

\section{Referencias Citadas}

Calle, $\mathrm{M}$.

2013 La inmigración europea en la provincia de Tarapacá. Su inserción en la estructura productiva, 1860-1940. En Sergio González Miranda (comp). La sociedad del salitre. Protagonistas, migraciones, cultura urbana y espacios públicos.119-163. Santiago: RIL Editores.

Calo, L.

2013 La emigración italiana en Bolivia desde la Colonia hasta el siglo XX. Relaciones políticas, económicas y culturales. En Anuario 2013. Sucre, Bolivia: Archivo y Biblioteca Nacional de Bolivia.

Cortese, L.

2011 El fascismo en el Club Italiano. Buenos Aires (1922-1945). En Rivista dell'Istituto di Storia dell'Europa Mediterranea, $\mathrm{N}^{\circ} 6$.

Díaz, A.

1998 Visión de la Problemática Política y Social de Tacna y Arica, a través de la Prensa Local: 1918-1926. Temas Regionales 1: 200-217.

Díaz, A.

1998 Impacto del Tratado de 1929 entre Chile y Perú sobre la estructura social y económica de Arica. Temas Regionales 92: 128-137.

Díaz, A.

2000 Presencia Italiana en la Ciudad de Arica, 1885-1950. Ediciones Universidad de Tarapacá, Arica, Chile.

Díaz, A.

2002 Apuntes sobre los italianos en la provincia de Tarapacá (1870-1950). En Amérique Latine, Histoire y Mémoire. $\mathrm{N}^{\circ} 5$. https://alhim.revues.org/715

Díaz, A.; E. Pizarro

2004 Algunos antecedentes de la presencia italiana en la ciudad de Tacna, 1885-1929. Revista Historia 7: 171-188.

Díaz, Alfonso; Díaz, Alberto; Sánchez, E.

2014 Comercio Local y Redes Sociales de la Población China en Arica y Tarapacá, Chile (1900-1930). Revista Interciencia, Volumen $39 \mathrm{~N}^{\circ} 7$.
Díaz, A.; R. Ruz, L. Galdames y A. Tapia

2012 El Arica peruano de ayer. Siglo XIX. Atenea N ${ }^{\circ}$ 505: 159-184.

Díaz, C.

1998 Italianos en Chile. Breve Historia de una Inmigración. Ediciones Documentas, Chile.

Donoso, C.; Ortiz, J.

2014 Iquique en la colección fotográfica Baselli (1891-1911). Iquique: Editorial Pino Oregón.

Estrada, B.

1993 Participación de italianos en la industria de Chile. Orígenes y evolución hasta 1930. En Presencia italiana en Chile. Ediciones Universitarias de Valparaíso, Chile. $227 \mathrm{pp}$.

Estrada, B.

2000 Los intentos estatales por estimular el factor humano nacional a través de la inmigración europea 1880 y 1920. Mapocho 47: 303-338.

Fanesi, R.

1994 El exilio antifascista en Argentina. Buenos Aires: Centro editor de America Latina.

Flores, A.

1991 Perú: identità e utopia. Ponte delle Grazie. Firenze, Italia. $452 \mathrm{pp}$.

Galdames, L.; R. Ruz y A. Díaz

2008 Arica y sus valles en el siglo XIX. Estudio del censo de 1866. Ediciones Universidad de Tarapacá, Chile. 321 pp.

González, S.

2008 La llave y el candado. El conflicto entre Perú y Chile por Tacna y Arica (1883-1929). LOM Ediciones. Chile. $222 \mathrm{pp}$.

González, S

2006 Arica y la triple frontera. Integración y conflicto entre Bolivia, Perú y Chile. Aríbalo. Chile. 166 pp.

McEvoy, C.

2006 Chile en el Perú: Guerra y construcción estatal en Sudamérica, 1881-1884. Revista de Indias LXVI (236): 195-216. 
Maino, V.

1988 Características de la Inmigración Italiana en Chile 1880-1987. Archivio Storico degli Italiani in Cile, Santiago, Chile. 72 pp.

Maldini, $\mathrm{H}$.

2004 Contando Italia desde Chile. Santiago: Editor Héctor Maldini.

Mazzei de Grazia, L.

1994 Inmigración y clase media en Chile. Proposiciones 24: 152-158.

Necochea, $\mathrm{H}$.

1978 El fascismo en la evolución política de Chile hasta 1970. En Araucaria de Chile $\mathrm{N}^{\circ} 1$.

Norambuena, C.

1995 La inmigración en el pensamiento de la intelectualidad chilena 1810-1920. Contribuciones Científicas y Tecnológicas $\mathrm{N}^{\circ} 109: 73-83$.

Payne, $\mathrm{S}$.

1979 El fascismo. Madrid: Alianza Editorial.

Pellegrin, Aprile

1926 El Censo Comercial Industrial de la Colonia Italiana en Chile. Editorial Río de la Plata, Santiago, Chile. 87 pp.

Pinto, J.

1993 La presencia italiana en el ciclo salitrero, 1860-1900. En Estrada, B. (Ed.). (1993), Serie Monografías Históricas 7. Valparaíso: Instituto de Historia-Universidad Católica de Valparaíso.

Ruz, R.; Díaz, A.

2013 Inmigración, cotidianidad y conflicto nacional en la biografía y archivo de Manuel Yanulaque Scorda (Inmigrantes griegos en Arica 1850-1934). Diálogo Andino 42: 57-67.
Savarino, F.

2009 Juego de ilusiones: Brasil, México y los "fascismos" latinoamericanos frente al fascismo italiano. En Historia critica. $\mathrm{N}^{\circ}$ 37. 120-147. Bogotá: Universidad de los Andes. 2002 Bajo el signo del Littoro: la comunidad italiana en México y el fascismo (1921-1944). En Revista Mexicana de Sociología. Vol. 64. № 2. México: UNAM.

Skuban, W.

2007 Lines in the sand. Nationalism and identity on the ChileanPeruvian frontier. University of México Press, EE.UU. 314 pp.

Ulianova, $\mathrm{O}$.

2009 Redes políticas y militancias: la historia política está de vuelta. Santiago: Ariadna.

\section{Fuentes}

\section{Periódicos}

El Tarapacá

La Provincia

Justicia

\section{Archivos}

Archivo de la Intendencia de Tarapacá, "Carabineros e Investigaciones 1942-1943”, ITAR-1795.

Archivo de la Intendencia de Tarapacá, "Ministerio del Interior 1943-1944”, ITAR-1802.

\section{Fuentes orales}

Mikele Manielo Evangelista, 82 años, jubilado, excomerciante. Giussepe Manielo Evangelista, 79 años, jubilado, exfuncionario del Servicio de Impuestos Internos.

Ernesto Gandolfo Batisttini, 93 años, empresario aún en actividad.

\section{Notas}

El Tarapacá, Iquique, 28 de octubre de 1928. Entrevista con Mikele Manielo. Entrevistador: Damián Lo, Iquique, 19 de noviembre de 2016.

La Provincia, Iquique, 29 de octubre de 1928.

El Tarapacá, Iquique, 30 de octubre de 1928.

El Tarapacá, Iquique, 28 de octubre de 1933.

Justicia, Iquique, 16 de octubre de 1933.

El Tarapacá, Iquique, 16 de octubre de 1933.

Entrevista con Mikele Manielo.

El Tarapacá, Iquique, 4 de noviembre de 1933.

El Tarapacá, Iquique, 5 de noviembre de 1935.

El Tarapacá, Iquique, 5 de noviembre de 1936.

El Tarapacá, Iquique, 23 de enero de 1936.

Entrevista con Ernesto Gandolfo. Entrevistador Damián Lo, Iquique, 20 de noviembre de 2016.
14 Archivo de la Intendencia de Tarapacá, "Carabineros e investigaciones 1942-1943”, ITAR-1795, № 23.

15 Frente Popular, Iquique, 28 de enero de 1943.

16 Entrevista con Mikele Manielo.

17 Véanse primeras fojas de telegramas sin número en "Ministerio del Interior 1943-1944", ITAR-1802.

18 Archivo de la Intendencia de Tarapacá, "Ministerio del interior 1943-1944", ITAR-1802.

19 Entrevista con Mikele Manielo.

20 El Tarapacá, Iquique, 26 de enero de 1943.

21 Entrevista con Ernesto Gandolfo.

22 Entrevista con Giuseppe Manielo. Entrevistador Damián Lo, Iquique, 15 de noviembre de 2016. 